\title{
THE RELATIONSHIP BETWEEN THE STAGE OF NASOPHARYNGEAL CARCINOMA WITH ANEMIA AND NUTRITIONAL STATUS IN WEST NUSA TENGGARA GENERAL HOSPITAL
}

\author{
Susilawati $^{*}$, Hamsu Kadriyan², Wayan Putu Sutirtayasa ${ }^{3}$ \\ ${ }^{I}$ Department of ENT-HNS Praya Hospital, West Nusa Tenggara; \\ ${ }^{2}$ Department of ENT-HNS Medical Faculty Mataram University/Provinsi Hospital West Nusa Tenggara; \\ ${ }^{3}$ Medical Faculty, Udayana University, Denpasar, Bali
}

\begin{abstract}
Introduction: Nasopharyngeal carcinoma (NPC) is the most common malignant tumour in otorhinolaryngology head and neck department. On the other hand, anemia and malnutrition were common problem among patients with cancer. Furthermore, chemotherapy and radiotherapy could also impact the anemia and nutritional status. Indeed, they could affect the quality of life and the survival.

Objective: To explore the relationship between the stage of NPC with anemia and nutritional status.

Method: Cross sectional study was done to analysed the relationship between the variables. Data was obtained retrospectively through medical records of patients with nasopharyngeal cancer in the West Nusa Tenggara general hospital who treated between January - December 2018. Data collection including the age, gender, stage of NPC, haemoglobin level, weight and height of all patients. To analyse the relationship between the variable, Anova testing were done to knows the relationship between the stage of nasopharyngeal carcinoma and anemia status. On the other hand. Kruskal Wallis was done for establishing the relationship between stage of NPC and body mass index (BMI).

Result: There were 38 patient included in this study, most of them in advanced stage, moderate anemia and undernutrition. There was no significant different between the stage of NPC and anemia severity with $\mathrm{p}$ value 0,849 . A similar result was found also on the relationship between the stage of NPC and malnutrition level with the $\mathrm{p}$ value 0,565 .
\end{abstract}

Conclusion: There was a tendency of anemia and malnutrition occurs in late stage of NPC, but the relationship between both variable to the stage of NPC were not different significantly.

\section{Article Info \\ Keywords: \\ Nasopharyngeal Carcinoma, anemia, BMI, nutritional status}

\section{*Corresponding author:}

Address: Basuki Rahmat 90, Praya, centre of Lombok

e-mail: susilawatiketut88@gmail.com

\section{INTRODUCTION}

Nasopharyngeal carcinoma (NPC) is the most common malignancy in otolaryngology head and neck surgery department. In Indonesia, NPC becoming the fourth frequent malignant tumour after breast, cervical and lung cancer [1].

There are several factors may related to the treatment of NPC , including, malnutrition, cachexia and anemia. Malnutrition and cachexia were common problem among cancer patients. They could impact the quality of life and affect the survival. Malnutrition and cachexia may occurs as a result of the serotonin and bombesin which was secreted by tumour cells. Hence, could suppress the appetite and increase the psychological factors such as depression and anxiety.Those factors, together with the effect of the treatment itself, such as chemotherapy, radiotherapy or surgery could induced the malnutrition and cachexia [2] Furthermore, due to reduced of oral intake, the endurance will be reduced and finally could result in body weight loss and the increase risk of secondary infection $[3,4]$. Approximately $50 \%$ of cancer patients have an experience on loss of body weight and the decrease of nutritional status at the time of diagnosis. Therefore determining the nutritional status and assessment of patients need at an early stage is very important [5-7]. Body mass index (BMI) is one of indicator in determining the nutritional status. BMI is expressed by the weight in kilograms which is divided by the square of the height in meters [8,9]. Nutritional status divided into several categories such as severe malnutrition if $\mathrm{BMI}<17.0$, mild malnutrition if BMI 17.0 to 18.5 , normal if $\mathrm{BMI}>18.5$ to 25.0 , mild obese $\mathrm{BMI}>25.0$ to 27.0 and severe obese if $\mathrm{BMI}>27.0$ [10].

Anemia is a major problem in patients with nasopharyngeal cancer. In Indonesia found more than $80 \%$ of patients with NPC were suffered from anemia [11]. Anemia is a hemoglobin level in red blood cells less than normal. United State National Cancer Institute divided anemia into five classification. Normal for men if $\mathrm{Hb}>12 \mathrm{~g} / \mathrm{dL}$, women if $\mathrm{Hb}>11$ $\mathrm{g} / \mathrm{dL}$, mild anemia if $\mathrm{Hb}>10.0 \mathrm{~g} / \mathrm{dL}$ to normal level, moderate if $\mathrm{Hb}$ between $8.0-10.0 \mathrm{~g} / \mathrm{dL}$, the severe if $\mathrm{Hb} 6,5-7.9 \mathrm{~g} / \mathrm{dL}$ and extremely severe if $\mathrm{Hb}<6,5 \mathrm{~g} / \mathrm{dL}[12,13]$

The cancer stage is a very important indicators on decision making for the treatment management as well as on predicting the prognosis. The more advanced the cancer, the treatment would be more complex and the prognosis would be worst. Unfortunately, nutritional status and anemia were found more frequent in advanced stage [11,12]. Several question arise regarding those facts, including the relationship between the stage of NPC with anemia and nutritional status. Finally, this study would analysed the independent effect of anemia and nutritional status on the NPC stage.

\section{MATERIAL AND METHODS}

Cross sectional study was done to analysed the relationship between the variables. Data was obtained retrospectively through medical records of patients with nasopharyngeal cancer in the West Nusa Tenggara general hospital who treated between January - December 2018. Several data including the age,gender, stage of NPC, haemoglobin level, weight and height of all patients would be collected. The stage of NPC would be categorised according to NCCN 2019. Anemia will be categorised according to United State National Cancer Institute. The BMI will be calculated through the weight $(\mathrm{kg})$ and height $(\mathrm{m})$ data and will be categorised according to Indonesian Nutritional Board. A Shapiro Wilcoxon test was done to know the normality distribution of the data. To analyse the relationship between the variable if the data distributed normally, Anova testing will be done. On the other hand if abnormal then Kruskal-Wallis would be done. 


\section{RESULT}

According to the data collection, there were 38 patients who fulfil the study criteria. The most NPC patients were in advanced stage $(92.11 \%)$, the age between 41-60 years old (52.63\%), male sex (60.53\%). Anemia and malnutrition were predominant than normal level among NPC patients. A moderate anemia was the most finding $(42.10 \%)$ in this study. Under nutrition was found in $47.4 \%$ subject. The complete data were showed at table 1 .

Table 1. Characteristics of patients with NPC according to the age, gender, stage, anemia and malnutrition status

\begin{tabular}{lcc}
\hline Characteristics of respondents & Number $(\mathbf{n})$ & Percentage $(\boldsymbol{\%})$ \\
\hline Age & 1 & 2.63 \\
$<21$ & 11 & 28.95 \\
$21-41$ & 20 & 52.63 \\
$41-60$ & 6 & 15.79 \\
\hline -61 & 23 & 60.53 \\
\hline Gender & 15 & 39.47 \\
Man & & \\
Woman & 0 & 0 \\
\hline Stage Cancer & 3 & 7.895 \\
Stage I & 19 & 50.00 \\
Stage II & 13 & 34.21 \\
Stage III & 3 & 7.895 \\
Stage IV A & & \\
Stage IV B & 10 & 26.32 \\
\hline Anemia Status & 11 & 28,95 \\
Normal & 16 & 42.10 \\
Mild & 1 & 2.63 \\
Moderate & 0 & 0 \\
Severe & & \\
Extremely severe & 13 & 34.21 \\
\hline BMI & 5 & 13.16 \\
Severe Malnutrition & 15 & 39.47 \\
Mild Malnutrition & 4 & 10.53 \\
Normal & 1 & 2.63 \\
Mild Obese & $\mathbf{1 0 0}$ \\
Severe Obese & & \\
\hline TOTAL & & \\
\hline
\end{tabular}

Table 2. The distribution of anemia status and BMI index according to the stage of NPC

\begin{tabular}{|c|c|c|c|c|c|c|}
\hline \multicolumn{7}{|c|}{ Stage Nasopharyngeal Carcinoma } \\
\hline & I & II & III & IV A & IV B & $\begin{array}{c}\text { Analysis } \\
\text { inferential }\end{array}$ \\
\hline \multicolumn{7}{|l|}{ Anemia Status } \\
\hline Normal & - & - & $6(15.79)$ & $4(10.53)$ & - & \multirow{5}{*}{$\begin{array}{c}\text { Anova } 0,167 \\
\text { P-value } 0,847\end{array}$} \\
\hline Mild & - & $1(2.63)$ & $5(13.16)$ & $3(7.895)$ & $2(5.27)$ & \\
\hline Moderate & - & $2(5.27)$ & $7(36.84)$ & $6(15.79)$ & $1(2.63)$ & \\
\hline Severe & - & - & $1(2.63)$ & - & - & \\
\hline $\begin{array}{l}\text { Extremely } \\
\text { severe }\end{array}$ & - & - & - & - & - & \\
\hline TOTAL & - & $3(7.895)$ & $19(50.00)$ & $13(34.21)$ & (7.895) & \\
\hline \multicolumn{7}{|l|}{ BMI } \\
\hline Severe & - & $2(5.27)$ & $5(13.16)$ & $6(15.79)$ & - & \multirow{7}{*}{$\begin{array}{c}\text { Kruskal } \\
\text { Wallis } 1,140 \\
\text { P-value } 0,565\end{array}$} \\
\hline Malnutrition & - & & $2(5.27)$ & $3(7.895)$ & - & \\
\hline Mild & - & $1(2.63)$ & $6(15.79)$ & $5(13.16)$ & (7.895) & \\
\hline Malnutrition & - & - & $4(10.53)$ & - & - & \\
\hline Normal & - & - & $1(2.63)$ & - & - & \\
\hline \multirow{2}{*}{\multicolumn{6}{|c|}{$\begin{array}{l}\text { Mild Obese } \\
\text { Severe Obese }\end{array}$}} & \\
\hline & & & & & & \\
\hline TOTAL & - & $3(7.895)$ & $18(47.37)$ & $14(36.84)$ & $3(7.895)$ & \\
\hline
\end{tabular}

According to table above, anemia was found predominantly at stage III followed by stage IV consecutively with $50.0 \%$ and $42.1 \%$. According to normality analysis, the distribution was normal, hence, Anova was done to analysis the relationship between the stage of NPC and anemia status. The result was 0.167 and $\mathrm{p}$ value 0.847 . According to BMI Index, malnutrition was found dominantly in stage IV and followed by stage III with the percentage $23.6 \%$ and $18.4 \%$ sequentially. The normality analysis found the distribution was abnormal, hence, the Kruskal-Wallis analysis was done to established the relationships between stage of NPC and nutritional status. The result was 1.140 and P-value 0.565 . Based on both analysis, the relationship was not significant.

\section{DISCUSSION}

Similar with the previous reports, in this study, NPC patients was frequently found in fourth decades of life, men was more affected than women and predominantly in advanced stage $[1,11]$. The finding of anemia in this study also equal to the other reports (70\% vs $80 \%)$ [11]. Regarding the nutritional status, this result was comparable with other study $(47.4 \%$ vs $30-50 \%)$ [15].
There are several factors may affected the occurrence of anemia in cancer, however, the lack of oral iron intake, low level of iron absorption and the presence of inhibitors for absorption were the main cause. This condition will led to reduction of iron reserves in the body and finally will result in anemia [15]. The treatment of cancer with chemotherapy and radiotherapy will suppress the bone marrow and will also result in low level of haemoglobin [16]. Indeed, anemia will be found frequently in patients with cancer.

The mechanism on the occurrence of malnutrition was quite similar to the anemia. Low intake of food containing macro and micronutrient as well as absorption disorder will led to undernutrition. Low intake of food may related to the low appetite, psychology and the effect of the cancer treatment itself. $[2,15]$ Hence, its logic that undernutrition will be found frequently amoung cancer patient, including NPC.

Staging in cancer was very important, not only for making a decision of treatment but also for predicting the prognosis. On the other hand, the level of $\mathrm{Hb}$ and nutritional status could altered the result of the treatment as well as impact the prognosis [15]. The more severe the stage of NPC, the risk of anemia and undernutrition will higher. However, according to our study, there was no significant relationship between stage of NPC with anemia severity and malnutrition severity.

Kadriyan et al., (2019) found the pattern of anemia was following the severity of the NPC stage, although its not significantly different between the stage [11]. A similar result was reported by Trijayanti et al,, (2016) who found there was no significant correlation between the stage and nutritional status, however the undernutrition was found predominantly in the advance stage cancer [16]. This result could be explained because anemia and undernutrition not only occurs because of the cancer stage, but also by the other factors such as the type of the tumour, organ involved, treatment given and the occurrence of the other disease [15]

In the future, a better research should be conduct to increase the validity of this study. The limitation of this study including the retrospective method and a relatively small sample size.

\section{CONCLUSION}

There was a tendency that the severity anemia was more frequent in the advanced stage. The similar finding on the undernutrition was predominant in more advanced stage. However, the relationship between the stage of NPC with the severity of anemia and undernutrition level was no significantly difference. A further research should be done with the better methods and bigger sample size.

\section{REFERENCE}

[1] Ferlay J SIea. Cancer incidence and mortality worldwide: sources, methods and major patterns in GLOBOCAN 2012. Int.J. Cancer. $2015 ; 136$.

[2] Rivadeniera DE. Nutrition support of the cancer patient. CA Cancer J Clin 1998: 48: 69-80

[3] Kenway Ng, SF Leung Johson PJ, Woo J. Nutritional consequences of radiotherapy in the nasopharynx Cancer Patients. In Nutrition and Cancer. 2004; 2: 156-61.

[4] Wood K. Audit of nutritional guidelines for head and neck cancer Patients undergoing radioterapy. The British Dietetic Ltd Dietet 2005. J Hum Nutr. 2005; 18: 343-51.

[5] Mutlu EA, Mobarhan S. Nutrition in the care of the cancer patient. Nutrition in Clinical Care 2000: 3: 1: 3-23

[6] Gionatti L., O. Genthilini, Braga M. Nutrition in oncological surgery. Inside: Cancer and Nutrition: Prevention and treatment. Nestle nutrition workshop series of clinical and program performance no. 4 Switzerland: Nest. Ed Ltd, 2000: 239-51

[7] Metterresse LE, Gottschilch MM, eds. Contemporary nutrition support practice. A clinical guide. 1st ed Philadelphia: WB Saunders Company, 2003: 484-508

[8] Goselin TK, Linda. Assesing the need for dietitian in radiation oncology. Clinical journal of oncology nursing 2008; 12: 781-7.

[9] Tierney LM, Mc Phee SJ, Papadakis MA editor. Current Medical Diagnosis and Therapy. New York: Mc Graw-Hill Companies, 2005; h.1695-8.

[10] Supariasa, et al.2002.'Nutritional Status Assessment”.Jakarta:EGC Medical Book Publisher.

[11] Kadriyan H, Sulaksana MA, Lestarini IA, Susilawati NK, Punagi AQ, et al. Incidence and characteristics of anaemia among atients with 
nasopharyngeal carcinoma in Lombok, Indonesia. AIP conference procceding.2019;2199(070015). https://doi org/10.1063/1.5141329

[12] Groopman JE, Itri LM. Chemotherapy-induced anemia in adults: incidence and treatment. J Natl Cancer Inst 1999; 91: 1616-34.

[13] Zhang ZN, T. Shen editors. Hematopathy diagnosis and curative standard. Beijing: science publishing house, 2007: 5-6.

[14] Aziz, FM, Adrijono., Saifuddin, AB 2010. The National Reference Books: Gynecological Oncology. Jakarta: PT Bina Library Prawirohardjo Sarwono.

[15] Perkeni. (2006). Surabaya Diabetes Workshop 7: Diabetes and Nutrition RSU Dr.Soetomo. Surabaya: FK Unair.108-119

[16] Trijayanti E, Probosari E. Relations food intake and nutritional status in patients with cervical cancer post kemoterapi.2016; 5: 751-760. 